\title{
Hippophae rhamnoides Fruit Oil
}

National Cancer Institute

\section{Source}

National Cancer Institute. Hippophae rhamnoides Fruit Oil. NCI Thesaurus. Code C107314.

The oil extracted from the fruit of Hippophae rhamnoides. Sea buckhorn fruit oil is used primarily in skincare preparations. 